\title{
Surveying and Engineering: Principles and Practice
}

\section{Paul Watson et al.}

Blackwell Publishing Ltd, Oxford; 2007: ISBN 9781405159234; 304pp; £34.99; paperback

Journal of Building Appraisal (2008) 4, 139. doi:10.1057/jba.2008.25

This book seeks to provide an up-to-date overview of the legislative requirements and practical demands required upon the modern construction professional in what is cited as being an increasing requirement for the construction professional that can diversify outside of the traditional professional boundaries. To this end, the book has brought together experts in a number of management, surveying, construction, and construction engineering disciplines. Each expert has provided a specialist chapter that allows for an overview of a phase of a construction project, not typically found within the reader's particular specialism. The target readership is final year students across all the construction and property professional disciplines, and current practitioners in those disciplines.

Given the target audience, this book is excellent. As many of the authors have sought to defy the wordage limitations of a single chapter by providing a wealth of technical information, any but the most gifted or experienced of lower level students might struggle with the technical content. The book does, however, provide a comprehensive overview, of a typical construction project and the reviewer sees it as of particular help to final year students looking to start a thesis. It is fully expected that this volume will be cited extensively in future construction-based dissertations. The provision of extensive lists of further reading will prove very useful to such student ventures.

Owing to a diversity of authors, the style of writing does vary between chapters; however, each is well crafted, makes maximum use of the space allowed, and appears to reflect the cutting edge of current professional practice. The illustrations used are generally appropriate and reader-friendly. The reviewer would strongly recommend this book for the target audience of final year students and current practitioners. There is no doubt that the construction industry is seeking to blur the edges of the traditional boundaries of professional specialism, and the multi-skilled or multi-conversant professional is going to be in greater demand. Any book such as this, which encourages interdisciplinary understanding, is therefore to be applauded.

In summary, the reviewer's opinion is that this is a very well-crafted, well-conceived, and well-executed text book, and the reviewer can only recommend it to those inside the target audience, and hope that those tasked with educating our future construction professionals will make use of both it and the message for the future of the construction professions that it conveys. At $£ 34.99$ it is an expensive book, but in the reviewer’s opinion still worth the investment for those serious about a career within a construction profession.

Simon Mclean

Managing Editor 